Review Articles

\title{
We are Addicted to Vitamins C and E-A Review
}

\author{
${ }^{1}$ Raffaella Aversa, ${ }^{2}$ Relly Victoria V. Petrescu, ${ }^{1}$ Antonio Apicella and ${ }^{2}$ Florian Ion T. Petrescu \\ ${ }^{1}$ Advanced Material Lab, Department of Architecture and Industrial Design, \\ Second University of Naples, 81031 Aversa (CE) Italy \\ ${ }^{2}$ IFToMM, ARoTMM, Bucharest Polytechnic University, Bucharest, (CE) Romania
}

Article history

Received: 11-11-2016

Revised: 12-11-2016

Accepted: 17-11-2016

Corresponding Author: Florian Ion T. Petrescu IFToMM, ARoTMM,

Bucharest Polytechnic

University, Bucharest, (CE)

Romania

Email: petrescuflorian@yahoo.com

\begin{abstract}
A Canadian researchers team led by dr. GC Willis, found that heart diseases are caused by hidden forms of scurvy and chronic and can be cured with high doses of vitamin $\mathrm{C}$ without heart surgery and drug treatments costly and with effects devastating side in organic plan. But the process of healing cardiovascular disease with vitamin $\mathrm{C}$ is not approved by the medical institutions and the pharmaceutical industry, which earns billions of dollars in surgeries and drugs that are used in allopathic therapies for various cardiac diseases. Canadian scientist discovery was confirmed in the late $80 \mathrm{~s}$ by Dr. Linus Pauling, Nobel laureate, the most noted human of his time. The medical care developed by Dr. Pauling include vitamin $\mathrm{C}$ with added lysine (amino acid nutritional qualities, existing in most plant and animal proteins) and it works cleanly, healing cardiopathy once thought were incurable. Dr. Pauling medical care records healing miracles coronary diseases. It had been identified back then that vitamin $\mathrm{C}$ deficiency within the body weakens human arteries by forming induration of the arteries plaques (infiltration of the walls of the artery and arteries with fat), that blocks blood circulation. This paper aims to spotlight the importance of vitamin $\mathrm{C}$ for the treatment and prevention of circulatory diseases especially. The daily minimum demand of vitamin $\mathrm{C}$ at tissues and cells level for a healthy person is: $75 \mathrm{mg} /$ day women, $90 \mathrm{mg} /$ day for men, $100 \mathrm{mg} /$ day smokers. But always need a bigger tank because these amounts could reach all tissues and cells of a healthy organism: about 500-1000 $\mathrm{mg} /$ day. When the body is disturbed or ill, quantities required to repair cells, are much higher 5000-10000 mg/day.
\end{abstract}

Keywords: Bioengineering, Biotechnologies, Vitamin E, Biochemical Processes, Predispose to Diseases, Cardiac Diseases, Healing Heart Diseases, Vitamin C Therapy

\section{Introduction}

Vitamin $\mathrm{C}$ is a water-soluble vitamin sensitive to heat and light, which plays an important role in the metabolism of humans and many other mammals. Chemically speaking, it is L-ascorbic acid, one of the stereoisomers of ascorbic acid and its salts, ascorbates. The most common are sodium ascorbate and calcium ascorbate.

Vitamin $\mathrm{C}$ is an enzymatic cofactor involved in a number of physiological reactions (hydroxylation). It is required in the synthesis of collagen and red blood cells and contributes to the immune system. It also plays a role in iron metabolism as a promoter of its absorption; Its use is therefore deprecated in patients with iron overload and particularly hemochromatosis. In oxidized form (dehydroascorbic acid), it passes through the bloodbrain barrier to access the brain and several organs with a high concentration of vitamin C. Skeletal muscles quickly respond to vitamin $\mathrm{C}$ intake, but also rapidly lose it, Vitamin intake is insufficient. It is an antioxidant, a molecule capable of countering the harmful action of oxidants such as radicals. For this purpose, D-ascorbic acid is also used which, unlike L-ascorbic acid, does not exhibit vitamin activity. Very fragile in solution, it is destroyed in contact with air (by oxidation) or under exposure to light (by ultraviolet action) and heat accelerates these processes. The heat of cooking food destroys vitamin $\mathrm{C}$.

While most mammals are capable of synthesizing it in their liver or kidneys (this is not a vitamin for 
them), the majority of primates (including humans), guinea pigs and some Birds and fish are unable to do so. This would be the result of a genetic mutation that occurred 40 million years ago, blocking the transformation of glucose into ascorbic acid. Animals lacking this ability to synthesize vitamin $\mathrm{C}$ must therefore draw it from their diet.

Several hypotheses have been formulated to explain the loss, in the ancestor of humans and great apes, of the ability to produce vitamin C. Richard J. Johnson, a specialist in cardiovascular disease and uric acid (Another genetic error practically characteristic of large primates, including humans), suggests that uric acid and the lack of vitamin C, two pro-inflammatory factors, would have given an evolutionary advantage by promoting fat retention Recognized for oxidative stress and inflammation), useful during the late Eocene and Middle Miocene famines, contemporaneous with these genetic mutations.

The European guidelines recommend a daily intake of $75 \mathrm{mg}$ for a woman and $90 \mathrm{mg}$ for a man. For example, an orange brings on average $53 \mathrm{mg}$ of vitamin $\mathrm{C}$ (40 to $80 \mathrm{mg}$ per $100 \mathrm{~g})$.

\section{Guinea Pig}

The guinea pig is one of the few species that share with primates the inability to produce vitamin C.

In France, AFSSA recommends a daily intake of 110 $\mathrm{mg}$ for an adult of 20 to 60 years. People exposed more to the harmful effects of oxidants, such as smokers, have an increased need for vitamin C (125 mg according to the Higher Council of Hygiene of Belgium). Some scientists, such as Linus Pauling (Nobel Prize for Chemistry in 1954), consider that the recommended dietary intakes should be at least $6,000 \mathrm{mg}$ or even $18,000 \mathrm{mg}$.

In free-ranging primates, nutritional analyzes show a daily intake of 2,000-8,000 $\mathrm{mg}$ per day for primates of comparable weight (chimpanzees) or slightly higher (gorillas) than those of humans. $25 \mathrm{mg}$ of vitamin $\mathrm{C}$ per kilogram of weight is recommended for all primates in captivity, i.e., for a chimpanzee of average weight (70 $\mathrm{kg}), 1750 \mathrm{mg}$ per day.

NAC veterinarians recommend $20 \mathrm{mg}$ of vitamin $\mathrm{C}$ for guinea pigs and 30-60 mg for pregnant females, i.e., roughly half of the recommended intake for a human being with a body mass 80 times higher Average body mass of adult guinea pig is $1 \mathrm{~kg}$, that of the male human varies around $80 \mathrm{~kg}$.

A very rare vitamin $\mathrm{C}$ deficiency causes scurvy, when the intake is less than $10 \mathrm{mg}$ per day. The more discrete hypovitaminoses are widespread and result in asthenia, weight loss, headaches, bone pain, increased susceptibility to infections and sometimes haemorrhagic problems.

Vitamin $\mathrm{C}$ is non-toxic at doses usually absorbed for a healthy individual.
Since its synthesis in the $1930 \mathrm{~s}$, vitamin C is used at all doses throughout the world. The only side effects associated with its use that are established are benign diarrhea and diuretic action. These occur when consumed too quickly and in too great a quantity. Since the organism cannot store it, it eliminates the excess.

\section{Clinical Studies Show}

That vitamin $\mathrm{C}$ intake does not increase or even reduce the incidence of kidney stones;

That vitamin $\mathrm{C}$ has no mutagenic effect (study on doses up to $5000 \mathrm{mg}$ per day).

In vivo studies show that vitamin $C$, even in the presence of transition metals, has no mutagenic effect and instead protects cells from the mutagenic action of hydrogen peroxide.

Symptoms of vitamin C overdose may include: (and/or) nausea, vomiting, headache, rash, asthenia.

For doses above $500 \mathrm{mg} / \mathrm{d}$, an increase in oxalic acid production may induce a risk of oxalate kidney stones. This side effect is controversial by some studies. Indeed, plants that bring vitamin $\mathrm{C}$ also bring oxalates, resulting in confusion. Finally, other recent studies confirm the safety of vitamin C up to $2000 \mathrm{mg} / \mathrm{d}$.

Some authors, like Thomas Levy, support the safety of higher doses, 6 to $12 \mathrm{~g} / \mathrm{d}$ in optimal dose according to individuals. Levy notes that some symptoms observed between $500 \mathrm{mg}$ and $1000 \mathrm{mg} / \mathrm{d}$ are transient and due to suboptimal doses and disappear at higher concentrations, pointing out that often impact studies are based on high doses but (E.g., for cataract risk one study suggests doses of vitamin $\mathrm{C}$ and $\mathrm{E}$ combined with mean values of $1000 \mathrm{mg}$ and $100 \mathrm{mg}$, respectively). The most commonly used dose of vitamin $\mathrm{C}$ and vitamin $\mathrm{E}$ as single supplements was Estimated to be $\approx 1,000 \mathrm{mg}$ and $\approx 100 \mathrm{mg}$, respectively").

As a medical treatment, vitamin $\mathrm{C}$ has some recognized indications: The prevention or treatment of scurvy, avitaminosis $\mathrm{C}, \quad$ idiopathic methaemoglobinaemia of the infant and methaemoglobinemia in G6PD-deficient subjects.

It is a molecule commonly used in self-medication: More than $10 \%$ of Americans consume it.

Vitamin $\mathrm{C}$ administered intravenously would relieve fatigue within two hours, an effect that continued at least until the day following administration, which is notable as the pharmacokinetics of vitamin $\mathrm{C}$ intravenously predicts an increase Blood levels of vitamin $\mathrm{C}$ for only four to six hours. Oxidative stress, as assessed by the Free Oxygen Radicals Test (FORT) method, also decreased.

Orally, a moderate dose of vitamin C (500 mg) could reduce the feeling of fatigue and stress in obese people on a low calorie diet.

A common misconception is that vitamin $\mathrm{C}$ prevents sleep, but this may prove to be inaccurate. 
It is the punctual supplementation following a long deficit that would cause this effect, a sufficient supplementation in the longer term would even have the opposite effect that would help to fall a sleep.

This vitamin is widely used in self-medication in the common cold. It seems to shorten the duration of the symptoms and improve, at least in adults, the effectiveness in the child seems unproven.

In the 1970 s, American Linus Pauling (Nobel Prize for Chemistry in 1954 and Nobel Peace Prize in 1962) advocated $1 \mathrm{~g}$ of vitamin $\mathrm{C}$ per hour from the first symptoms to regress the infection. But today, studies tend to show that vitamin $\mathrm{C}$ has no preventive effect against the common cold. Some authors observe that meta-analyzes, such as the 2004 Cochrane Collaboration, which include only studies where the vitamin has been administered only once a day, do not disprove Pauling's assertions. Since 2013, the Cochrane Group recognizes that randomized trials are necessary and recommends, despite this, supplementation, given its low cost, potential benefits and accumulated weight of evidence.

In 1939, it was reported that 34 workers who had absorbed lead had been treated with vitamin C. Recently, an animal study showed that vitamin $\mathrm{C}$ had a protective effect against lead poisoning Nervous and muscular functions. In the case of smokers, administration of 1000 $\mathrm{mg}$ of vitamin $\mathrm{C}$ resulted in an average reduction of $81 \%$ in blood lead concentrations, while $200 \mathrm{mg}$ remained unchanged. The authors concluded that vitamin $\mathrm{C}$ supplementation could be an economical and practical way to lower lead levels in the blood. A study published in the Journal of the American Medical Association concludes that if the causal link was well demonstrated, the inverse correlation between lead and vitamin $\mathrm{C}$ in blood found in a national survey would have an impact on the public health plan in general.

One of the diseases most likely to be treated with pharmacological doses of ascorbate is AIDS. The controversy has been going on for more than 16 years, since the publication of a study to show that ascorbate, in non-toxic doses to humans, halted HIV replication in Proceedings of the National Academy of Sciences of the United States. Other studies by the same authors have followed and supported these findings, but no major clinical studies have been undertaken.

In the treatment of cancer, Linus Pauling, drawing inspiration from the work of Irwin Stone, gives the idea of a much higher ascorbic acid intake than suggested by the RDAs (of the order of 10 to 20 grams per day). A favorable effect appears to exist in cell cultures or in animals, in particular an inhibition of cell proliferation, but no satisfactory proof exists in human beings for curative or preventive purposes. In particular, the Swiss Society for the Fight against Cancer emphasizes the weaknesses in the scientific dossier of Matthias Rath, another promoter of the use of vitamin $\mathrm{C}$ against cancer. Matthias Rath was also convicted of unauthorized therapeutic trials and accused of killing HIV patients using vitamins as anti-HIV therapy in place of antiretrovirals.

According to a 2008 study by the American Institute of Health, ascorbic acid injected intravenously at high doses would halve the growth of laboratory mouse tumors.

In contrast, a study by Dr. Mark Heaney of Columbia University concludes that supplementation with vitamin $\mathrm{C}$ may decrease the efficacy of chemotherapy treatments by $30-70 \%$. For Fatima Mechta-Grigoriou, research director at Inserm and head of the stress and cancer team at the Institute Curie, this is a "very preliminary" analysis that does not tell us what impact Has vitamin C on the therapeutic effects of anticancer drugs.

In 2010, a meta-analysis reviewing 33 years of research on the relationship between vitamin $\mathrm{C}$ and cancer concludes: "We must conclude that we still do not know if vitamin $\mathrm{C}$ has any clinically significant antitumor activity. We also do not know which types of cancers, if any, are likely to react to vitamin C. Finally, we do not know what the recommended dose, if such a dose exists, in order to produce an antitumor response."

This analysis was criticized by Dr. Andrew W. Saul. The main points of his rejoinder are:

It is wrong to say that we do not know how much vitamin $\mathrm{C}$ effectively fights cancer and doctors have a duty to their patients to recommend vitamin $\mathrm{C}$ as a complementary treatment.

There are several studies with controls showing that vitamin $\mathrm{C}$ increases the duration and quality of life.

The effective dose is between 10,000 and 100,000 milligrams intravenously.

The positive results obtained by Pauling and Cameron, underlined by Cabanillas, were not contradicted by those of Moertel and the Mayo Clinic:

The treatments were interrupted at the first sign of aggravation, which is never done during chemotherapies.

The dose was administered orally and not intravenously, thus decreasing the dose actually absorbed (Nevertheless, the initial study of de Pauling and Cameron also included oral doses and their study was not randomized, Contrary to that made by the Mayo Clinic. The protocol, put in place by the Mayo Clinic, was done in agreement with Pauling, who rather refuted the results on the basis that chemo and radiation therapy could "damage" the immune system, but never attacked the oral doses protocol).

The results of Pauling and Cameron have in fact been confirmed by Murata and Lasagna:

Murata achieved even better results with its terminally ill patients.

Lasagna concluded that it was untenable not to give vitamin $\mathrm{C}$ to cancer patients.

The oncologist Victor Marcial reports that: 
About $75 \%$ of tumors decreased by $50 \%$ or more with intravenous vitamin $\mathrm{C}$ in 40 patients in stage 4 (with metastases) who did not respond to conventional treatments (radiotherapy, chemotherapy).

Vitamin $\mathrm{C}$ increases the effects of radiotherapy and reduces adverse effects.

These few favorable results should not overshadow all the others, unfavorable, not cited by Andrew W. Saul, highlighted in the meta-analysis.

Amounts between $1,000 \mathrm{mg}$ and $3,000 \mathrm{mg} / \mathrm{day}$ (divided into several doses due to a risk of renal toxicity) are proposed as a therapeutic trial in the treatment of an inherited neurological disease, CharcotMarie-Tooth type 1A. The clinical trial in these patients could only be considered after a preclinical trial, carried out on a murine model of the disease showing encouraging results.

Orthomolecular medicine advocated in particular by Linus Pauling, Nobel Prize in Chemistry, recommends a consumption of vitamin $\mathrm{C}$ of 2 to $20 \mathrm{~g}$ /day which can be increased in case of illness, based on the first works of Irwin Stone. Linus Pauling studied the role of vitamin C in the prevention of colds and the treatment of cancer. This vitamin, administered in appropriate form by appropriate techniques, in sufficiently frequent doses, in sufficiently high doses, in conjunction with certain agents and for a sufficient period of time, would be capable of preventing or even curing a large number of diseases, Including influenza, cancer or coronary heart disease. These hypotheses have not been confirmed by other larger and more recent studies, whether for influenza, cancer or cardiovascular disease.

It may be protective at the renal level, with a lower frequency of renal failure if an iodinated contrast agent is injected during a radiological examination.

In combination with other antioxidants, it may contribute to the prevention of age-related macular degeneration or even coronary artery disease.

Vitamin C could play an important role in the regulation of cholesterol synthesis.

Taking vitamin $\mathrm{C}$ may decrease the risk of gout.

Vitamin C, injected early intravenously, is part of the treatment of phalloid poisoning proposed by Dr. Pierre Bastien.

Age-related diseases and associated immune dysfunctions may be limited by absorption of vitamin $\mathrm{C}$ supplements.

In infertile men, vitamin $\mathrm{C}$ supplementation has been shown to improve sperm quality (morphology and sperm motility) and increase the number of spermatozoa.

Australian physician Archie Kalokerinos, adhering to Linus Pauling's theses on orthomolecular medicine and vitamin C, states in 1981 that the high infant mortality observed among aboriginal children and in particular sudden infant death, Due to a lack of vitamin $\mathrm{C}$ and therefore to scurvy and that this mortality would be further aggravated by the vaccinations. This hypothesis has never been validated by the scientific community.

The American doctor Claus Washington Jungeblut (en) issued in 1935 the hypothesis that vitamin $\mathrm{C}$ can inactivate the poliomyelitis virus. He published a series of papers between 1936 and 1939 in which he showed that the administration of ascorbic acid in infected monkeys decreased the severity of the disease. Albert Sabin tried to reproduce these results but did not succeed, which put an end to this way of research. Dr. Fred R. Klenner told the Applied Nutrition Association of the United States that Sabin had refused to follow Jungleblut's advice on the necessary vitamin $\mathrm{C}$ dose and had imposed a much higher viral load on his rhesus monkeys than in the initial experiences. Klenner, for his part, announced clinical results obtained in particular during the 1948 epidemic confirming the results of Jungleblut.

According to studies conducted in 1967 and 1993, vitamin $\mathrm{C}$ supplementation would decrease the severity of symptoms in children with autism, but the optimal dosage remains to be determined.

The appearance of multivisceral failure syndrome, which for traumatologists is one of the main signs of death, appears less frequently in patients receiving vitamin C; This vitamin also reduces the length of stay in intensive care.

Vitamin $\mathrm{C}$ would have a protective effect against nicotine on the lungs in formations of a fetus. Supplementation in pregnant smokers improves the respiratory function of the newborn and reduces the risk of wheezing.

The allergy could be caused by environmental pollutants that disrupt the histamine cycle. Several studies have shown that taking vitamin $\mathrm{C}$ has reduced or suppressed the symptoms of allergies. It also has an effect against asthma by replacing the bronchoconstrictor PGF2 synthesis with that of the bronchodilator PGE2. Finally, it protects against the accumulation of histamine.

Intestinal tolerance refers to the amount of vitamin $\mathrm{C}$ that can be absorbed by the intestine within a given time. When this amount is reached, the unabsorbed vitamin $\mathrm{C}$ is eliminated in the stool. During its journey, it attracts water into the intestine which produces transient diarrhea. This is one of the reasons why one cannot get intoxicated with vitamin C. Some scientists propose the hypothesis that vitamin $\mathrm{C}$ is a water-soluble vitamin, insufficient intake of dilution water at the time of vitamin intake $\mathrm{C}$ could be the cause of intestinal disorders.

The quantities produced by the animals vary according to their state of stress and health. A stressed or sick animal can produce several tens of grams per day. This variable production of ascorbate in animals can be compared with the variability of intestinal tolerance in 
humans. When a human is sick or stressed, his intestinal tolerance to vitamin $\mathrm{C}$ increases, allowing him to absorb more vitamin $\mathrm{C}$ than normal. Variability in intestinal tolerance suggests an increased need for vitamin $\mathrm{C}$ in periods of stress or disease, as seen in animals that synthesize vitamin C (Vitamine C. Wikipedia).

If we consider the statistics established by WHO regarding the annual deaths caused by coronary artery disease, since the discovery made by Canadian researchers in the 50s until today, were billion earthlings which died of cardiovascular disease, that could be cured with vitamin $\mathrm{C}$, if mankind could have benefited by the experimental results of Canadian researchers team. Deaths from heart disease (caused by chronic scurvy) could be avoided by a simple treatment with vitamin C (Willis, 1953, 1957; Willis et al., 1954).

What are not told to the patients is the fact that open heart surgery fails in $40-50 \%$ proportion of cases, since the disease soon recurs after surgery. Solving the most safe and effective known heart disease, it consists of daily administration of a dose of 6000 to $10,000 \mathrm{mg}$ vitamin C (Abdul-Razzak et al., 2012; Abou-Zeid, 2014; Ahmed et al., 2011; Ajith et al., 2007; 2009; Antunes et al., 2000; Atasayar et al., 2009; Babaev et al., 2010; 2011; Barja et al., 1994).

It was known long ago that vitamin $\mathrm{C}$ deficiency in the body weakens human arteries by forming atherosclerotic plaques (infiltration of the walls of the aorta and arteries with fat), which blocks blood circulation. Dr. Pauling and his team found that upon submission of atheromatous plaques within the arteries, often occurs rupture of a weakened artery and resulting blood clots that lead to heart attack or stroke.

Scurvy chronic responsible for heart disease, it was confirmed by cardioretinometry and was healed by daily doses of vitamin C, by Dr. Sidney Bush, from UK. Dr. Sidney Bush noted that building plagues are reduced and disappear following daily doses of up to $10,000 \mathrm{mg}$ vitamin $\mathrm{C}$. Based on these observations he developed a new method of diagnosing coronary disease, called cardioretinometry (Vitamin C Foundation).

Pericorneal vascularization demonstrates that all people are affected at some point by scurvy, most of them suffering from this condition all the time. Chronic subclinical form, unknown widely, can be diagnosed using sequential electronic retinal arterial images and cured by varying amounts of vitamin $\mathrm{C}$ associated with some nutrients (Buzea et al., 2015; Calderon et al., 2002; El-Gendy et al., 2009; Enstrom, 2014; Gladys Block; Ha et al., 2010; Hansen et al., 2014; Hickey and Roberts, 2007; Kalender et al., 2010; Kunutsor et al., 2016; Marín et al., 2014; Matsuda et al., 1992; Nakata and Maeda, 2002; Nefic, 2001; Noh et al., 2005; Petrescu et al., 2015; Petrescu and Petrescu, 2015; Pierce et al., 2013; Rath and Pauling, 1990; Rath, 2003; Ravnskov, 2009;
Salama et al., 2013; Santos et al., 2008; Seo and Lee, 2002; Shalan et al., 2005; Sun et al., 2000; Ulatowski et al., 2011; 2014; Ulatowski and Manor, 2015; Verrax et al., 2003; Verrax and Calderon, 2008; Vitamin C Foundation; WALTER BLUMER; Willis, 1953; 1957; Willis et al., 1954; WSite of Richard T. Lee; WSite Charles Hennekens; Xavier et al., 2007; Yévenes et al., 2012; Yilmaz et al., 2006; Robert F. Cathcart; Yousef, 2004; Vitamine C. Wikipedia).

\section{Materials and Methods}

Free Radicals meet many critical functions in our body, checking blood passing through artery up to the fight against infection. Some free radical signal molecules that is responsible for starting and stopping of genes. Some free radicals, such as nitric oxide and superoxide, are produced in large quantities by our cells immune to "poison" viruses and bacteria. However in less than a second, free radicals may turn against us, we may sicken and we can grow old too fast. Where there is a stroke or a heart attack, or just an inflammatory disease such as arthritis, free radicals are existing or in production. For us to understand what are free radicals must be known human cells, where every day and every second, is wearing a war between free radicals and antioxidants. As anything in the universe and the cells are made up from smaller units called atoms. Each atom contains a nucleus that is surrounded by electrons. Two or more atoms may be linked by dividing electrons forming molecules. The biological process of oxidation (the process of training of energy), involve the transfer electrons from an oxygen molecule to the next. For these reasons sometimes may escape one lone electron. An atom remained without one electron (an ion) present in human body, bears the name of a free radical. Free radicals are formed constantly almost everywhere in the body in an amazing proportion. If free radicals spread by all over the body are not caught, may attack and oxidize DNA, genetic material that controls growth and development of cells, promote spiral down premature aging, or may cause many other heavy damage by intoxicating the body (Ha et al., 2010).

Many people consume network antioxidants-vitamin C, vitamin E, lipoic acid, coenzyme Q10, glutathione, etc because they want to look and feel younger (Petrescu et al., 2015; Pierce et al., 2013; Rath and Pauling, 1990; Rath, 2003; Ravnskov, 2009; Salama et al., 2013; Santos et al., 2008; Seo and Lee, 2002; Shalan et al., 2005; Sun et al., 2000; Ulatowski et al., 2011; 2014; Ulatowski and Manor, 2015; Verrax et al., 2003; Verrax and Calderon, 2008; Vitamin C Foundation; WALTER BLUMER; Willis, 1953; 1957; Willis et al., 1954; WSite of Richard T. Lee; WSite Charles Hennekens; Xavier et al., 2007; Yévenes et al., 2012; Yilmaz et al., 2006; Robert F. Cathcart; Yousef, 2004). Keeping antioxidant use -i.e., 
keeping free radicals in check can be one of the most effective ways to slow the aging process. Antioxidants network (network of special antioxidants) work together in the body. Only five are considered the network antioxidants: Vitamin C, Vitamin E, lipoic acid, coenzyme Q10 and glutathione. Vitamin $\mathrm{C}$ and $\mathrm{E}$ are not produced by our body but must be obtained through food (Abdul-Razzak et al., 2012; Abou-Zeid, 2014; Ahmed et al., 2011; Ajith et al., 2007; 2009; Antunes et al., 2000; Atasayar et al., 2009; Babaev et al., 2010; 2011; Barja et al., 1994).

When an antioxidant encounters a free radical, the radical is automatically joined to antioxidant molecular structure (El-Gendy et al., 2009; Enstrom, 2014; Gladys Block). Antioxidant becomes a new type of free radical, harmless.

This will exempt cells and tissue destructive action of a radically freely got out of control. What really makes the network of antioxidants to be special is that they can "recycle" or regenerate after they were loosened a radically free, widening and more power. For example: When Vitamin $\mathrm{C}$ triggers a radically free it becomes weak free radical in the process. This anti-oxidant can be recycled in the form of vitamin $\mathrm{C}$. As an anti-oxidant network saves him on the other side, cycle continues by making sure that the body will keep the correct balance of the antioxidants. This particular scenario - the antioxidant meets a free radical-it take it, becomes a free radical friend-is recycled for another antioxidant network - occurs repeatedly in the body, in the blink of an eye.

Research has estimated that the number knocks oxidative degradation administered daily DNA in each cell is 10,000 and if this figure is multiplied by the millions of cells in the body can be understood the scale of such processes in the human body. Each antioxidant has a unique niche in the cell; for example in the areas of aqueous cell or in the blood, which consists primarily of water, they will act only vitamin $\mathrm{C}$ and glutathione.

Vitamin C prevents skin cancer, guarding DNA of threat free radicals. In normal amounts Vitamin $\mathrm{C}$ provides beautiful skin (Buzea et al., 2015; Calderon et al., 2002; Petrescu et al., 2015). Vitamin C is essential for collagen production cellular glue that holds the body bound and keeps skin young and supple. Vitamin C protects the body against health problems especially in the elderly. Vitamin $\mathrm{C}$ is considered the center of the antioxidant network, because the connection between fat-soluble antioxidants and the water soluble. Vitamin $\mathrm{C}$ is important for reloading a fatsoluble vitamin E (Pierce et al., 2013; Rath and Pauling, 1990; Rath, 2003; Ravnskov, 2009; Salama et al., 2013; Santos et al., 2008; Seo and Lee, 2002; Shalan et al., 2005; Sun et al., 2000; Ulatowski et al., 2011; 2014; Ulatowski and Manor, 2015; Verrax et al., 2003; Verrax and Calderon, 2008; Vitamin C Foundation; WALTER BLUMER; Willis, 1953; 1957; Willis et al., 1954; WSite of Richard T. Lee; WSite Charles Hennekens; Xavier et al., 2007; Yévenes et al., 2012; Yilmaz et al., 2006; Robert F. Cathcart; Yousef, 2004); when it becomes a free radical, it best meets function. Vitamin $\mathrm{C}$ (ascorbic acid) is found in the following foods: Citrus, green peppers, broccoli, blueberries, strawberries, tomatoes, cabbage (Fig. 1) (Buzea et al., 2015; Petrescu et al., 2015).

The daily minimum requirement of Vitamin $\mathrm{C}$ at tissues and cells level for a healthy man is: $90 \mathrm{mg} /$ day for men, $75 \mathrm{mg}$ /day women, $100 \mathrm{mg}$ /day smokers (Buzea et al., 2015; Petrescu et al., 2015).

But always need a bigger tank because these amounts could reach all tissues and cells of a healthy organism: about 500-1000 mg/day.

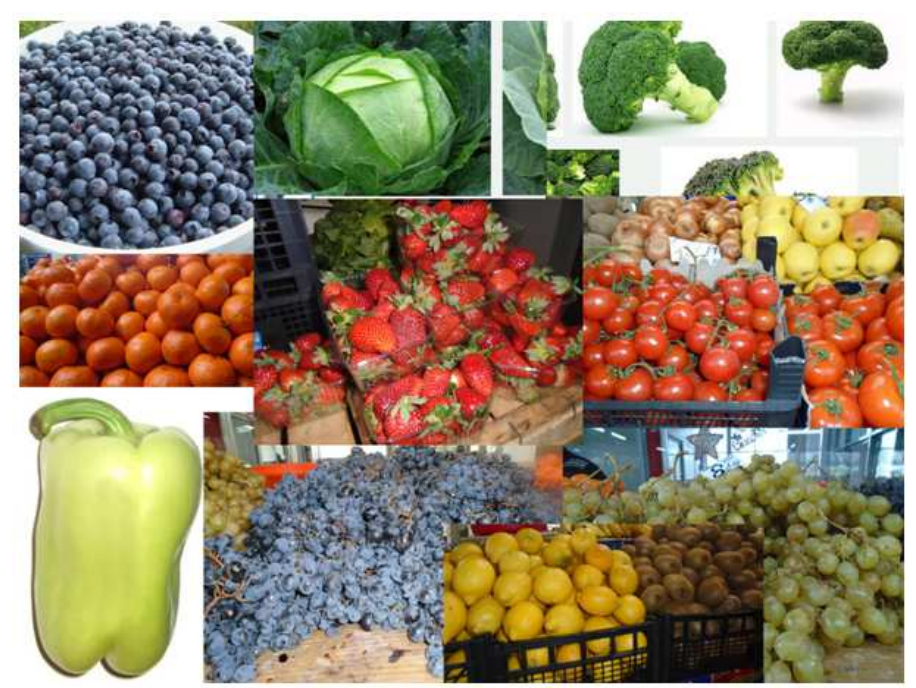

Fig. 1. Vitamin C (ascorbic acid) is found in the following foods: citrus, green peppers, broccoli, blueberries, strawberries, tomatoes, cabbage 
When the body is disturbed or ill, quantities needed to repair cells, are much higher $5000-10000 \mathrm{mg} /$ day.

Whenever, it is preferable to get our daily requirement of vitamin $\mathrm{C}$ only from food. But in tough conditions, when there is a diagnosed disorder or disease, the body having really need large amounts, must intervene urgently with high amounts of vitamin C synthesized.

\section{Results}

\section{Heart Disease Hindrance}

Canada's variety 2 killer, just behind cancer, is heart disease (Gladys Block; Ha et al., 2010; Hansen et al., 2014; Hickey and Roberts, 2007). It's the variety one cause of hospitalization and the price to the Canadian economy is staggering at $\$ 18.5$ billion per year! What is the first sign of a heart attack? A first sign in those situations means death.

Minimum $70 \%$ of the heart attacks take place in people with vas blockages that don't seem to be detectable by roentgenogram the foremost relied upon method of assessment used today. On the other hand more than 50\% of people with heart attack had normal cholesterol and $33 \%$ had no risk factors for cardiovascular diseases.

The natural treatments are made with individualized schemes to avoid the heart disease. Important and needed first step is to determine the health situation. These assessments include blood and urine laboratory testing. Computerized assessment measures stiffness of the major artery and the aorta. Aortic stiffness increases blood pressure and puts a strain on your heart. Moreover the heart frequency variability (which is an important indicator of stress of heart) is also measured (Gladys Block; Ha et al., 2010; Hansen et al., 2014; Hickey and Roberts, 2007; Kalender et al., 2010; Kunutsor et al., 2016; Marín et al., 2014; Matsuda et al., 1992; Nakata and Maeda, 2002; Nefic, 2001; Noh et al., 2005; Petrescu et al., 2015; Petrescu and Petrescu, 2015).

\section{Diet, Exercise and Weight Control}

Heart diseases prevention studies indicate that 93\% of patients can control their blood pressure with diet alone by consuming more vegetables and fruits and salt reducing. Studies, however, show that only $38 \%$ of patients were able to keep this regimen. Weight control also prevents heart disease but like diet, they are hard to keep up. In these situations medical treatment becomes a necessity.

\section{Removal of Heavy Metals}

Heart patients have twenty two, times more mercury and 14 times more antimony in their hearts. These toxins narrow the blood vessels and reduce the flow of the blood. Chelation therapy removes heavy metals resulting in the return the blood vessels to a normal functioning. Dr. W. Blumer, M.D., detoxified patients for 18 years and located a discount of $80 \%$ in cardiopathy (WALTER BLUMER).

\section{Strengthen Your Blood Vessels}

Dr. Linus Pauling, Ph.D., won 2 Nobel prizes in medication and with Dr. M. Rath, M.D., established a cure for heart disease and a way to prevent it (Rath and Pauling, 1990). They used high doses of aliment $C$ to strengthen the walls of blood vessels and stop the injury or breakdown of the walls that results in plaque built up and narrowing of the blood vessels. They additionally used high doses of essential amino acid, AN amino acid, to stop the excessive build up of plaque on the vessel walls. Taken along, vitamin $\mathrm{C}$ and lysine are clinically effective. Dr. Robert Cathcart, M.D. treated over 20,000 patients without one case of cardiopathy developing (Yilmaz et al., 2006).

\section{Decrease Inflammation in your Blood}

It may be stunning, however there are individuals with ninetieth blockages in their blood vessels that ne'er have a attack of heart and there are peoples with no blockages that had heart attacks.

Studies have indicated that infection and inflammation will trigger clots in your blood accountable for heart attacks, regardless of the condition of the blood vessels. The sore can be controlled by a testing blood $\mathrm{C}$ reactive protein, an inflammatory marker. Your blood is kept healthy when it taking some anti-oxidant, antiinflammatory or anti-thrombotic and macromolecule lowering natural medicines.

\section{What is Plaquex?}

Plaquex may be a mixture of essential phospholipids (phosphatidyl cholines) made of soybeans. Developed in Europe, it's been used primarily to get rid of the deposits of fatty plaque in arteries and different blood vessels.

\section{Vital Signs}

A testing of important life signs may determine your level on cardiovascular health and stress.

A sensor infrared is clipped to your ear and measures some changes in volume of blood momentary. In this time, a computer stores and interprets your arterial pulse. It gives the stiffness of your major artery, the aorta, where it comes out of your heart.

The aortic stiffness can increase the blood pressure and puts a strain on the heart; it results in less blood flow to the coronary arteries. If higher the aortic stiffness, there is a greater cardiovascular risk.

These Vital Signs may also determine your heart rate variability (which is an indicator of your level of stress) by monitoring the beat-by-beat timing of your heart. 
A high heart rate variability indicates low stress and it is associated with a good nervous system balance and a good health. When the muscle of heart is healthy, it will be able to speed up or slow down heaving decreases and increases in blood flow. An unhealthy heart can't speed up or slow down. A low or very low heart rate variability can be associated with increased risk of heart diseases.

\section{Cholesterol}

The high cholesterol is alleged by the pharmaceutical business as a serious risk factor for heart stress and disease. Some drugs [Lipitor, Zocor] which are used to reduce cholesterol are today the number one world medication. It has been told that high cholesterol will increase the risk of stroke and heart attack. But long-run studies have proved that these drugs do not generally change the rate of stroke and heart attack. Besides, more than $60 \%$ of people who die from a heart attack or a stroke had a normal or low cholesterol level.

\section{Cholesterol Genetically and High Cholesterol Needs Drugs}

The familial hypercholesterolemia (which is an inherited, genetic disorder where the liver is unable to produce an enzyme that lowers cholesterol) is a very serious problem. For this reason the result is extremely elevated cholesterol level. But these serious risks of diseases to persons which really need drugs occur only in one in 500 people.

\section{Any Body Requires Cholesterol}

Dr. U. Ravnskov, M.D., a great authority in the cholesterol theory, say that all drugs to lowering cholesterol are very dangerous for our health and can shorten our life. All these drugs are action by inhibiting the body's innate ability to produce its own cholesterol. When one blocks the own cholesterol production it is creating significant complications on body health. Generally, cholesterol is an important life element for our liver, skin, for brain health, for heart, etc. which are making the body's hormones, being particularly important when we age. When the hormone levels decrease our bodies respond with increased levels of cholesterol to supply the basic elements to raise our hormones levels (Ravnskov, 2009).

\section{Inflammation More Important}

Meanwhile the world experts in natural medicine claim the high cholesterol as a great risk factor, there are other factors contributing to the development of heart disease that are more significant. Thus with respect to heart disease, more comprehensive approach is needed. Some experts from Harvard have found that inflammation is one of the major causes of heart diseases. Today one knows that measured of blood levels by C-reactive protein (an inflammatory marker), inflammation is a critical indicator in need of investigation.

\section{Natural Options Reduce Cholesterol}

For people who still want to lower their cholesterol and are seeking another option to drug therapy, there are fortunately other alternatives such as red rice yeast extract, niacin, vitamin $\mathrm{C}$ and plant sterols. All these options can lower cholesterol levels can reduce unwanted and especially sluggish circulatory inflammation in the human body. Sterols from plants proved highly efficient in absorbing negative cholesterol in humans without affecting the level of HDL (the good cholesterol needed to the body).

\section{Natural Medicines Reduce Cardiovascular Risk}

The need to reduce negative human cholesterol levels started from the need to reduce the risk of cardiac or cerebrovascular accident. Natural medicines have today already a known history of success in preventing and especially treatment of heart disease, offering some alternative safe and effective treatments to classic pills (which after all are just drugs that do more harm to the body than good, dropping more the good cholesterol needed to the body).

\section{Heart Diseases}

Realistically most common sign of a heart attack is sudden death unfortunately. Who survived such an attack, however, it was the subject of multiple and difficult tested, treated with a lot of chemical drugs and perhaps unfortunately has had deregulate and one or more surgeries to control the disease. If in some extreme cases surgery and drugs are absolutely necessary today, in most cases they can be replaced by natural methods of treatment (alternative treatments) or when the disease is early (here the prevention can play an important role) or in situations the inflammation did not exceed certain limits.

\section{Heart Diseases Treatment without Drugs and Surgery}

The alternative (natural) medicine has today more effective and noninvasive treatment options. Therapy Pauling with lysine (an amino acid) and high doses of vitamin $\mathrm{C}$, already has a history officially recognized treatments successful in situations where the disease was early (preventive) and in difficult cases of some patients who already had suffered at least one attack stroke or heart, with one or multiple surgeries and heavy chemical treatments. Chelation therapy with intravenous injections consisting in an essential amino acid that removes heavy metals from the body, has a success rate globally certified $87 \%$. Another intravenous therapy, plaquex, became a primary treatment for heart disease due to its 
ability to reduce plaque deposited in the arteries. These alternative treatments are for those with heart failure who can cause fatigue, shortness of breath, angina and numbness in the limbs.

\section{Tame Inflammation}

Existing inflammation in the blood has been unanimously identified as a major cause of heart disease and C-reactive protein (which is measured by a simple blood test) can donate valuable information regarding your risk of a heart attack.

An oral or intravenous medication natural can be used to reduce inflammation. Homocysteine and lipoprotein levels can analyze and give useful information on identifying the risk of blood clots. Testing Vital Signs provides a measure of the health of the heart as a score that can identify health of the heart, specifically the aorta (the major artery). This last test computerized non-invasive blood flow also assesses the state of stress and nervous system learned about heart.

\section{Hormones Can Help}

There is a major connection between a hormonal imbalance and heart diseases, particularly testosterone, which when decreases clearly indicate that a weakness has appeared in the cardiovascular system.

Low levels of DHEA hormone limiting the ability of the heart to pump. If the test finds the level of these hormones is low, then a correction can be made by administration of natural hormones.

Vitamin E is a fat-soluble vitamin covering a set of eight organic molecules, four tocopherols and four tocotrienols. The biologically most active form is $\alpha$ tocopherol, the most abundant in the diet being $\gamma$ tocopherol. These molecules are present in large quantities in vegetable oils. They act, in parallel with vitamin $\mathrm{C}$ and glutathione, essentially as antioxidants against reactive oxygen derivatives produced in particular by the oxidation of fatty acids.

In 1922, embryologist Herbert McLean Evans (in) and assistant Katharine Scott Bishop of the University of California at Berkeley found that females in a lipiddepleted diet may become pregnant but no fetus expands. However, pregnancies come to term when the diet is supplemented with leaves of lettuce or wheat germ. The two scientists suspect the existence of a lipophilic compound, which they call Factor X, indispensable to the development of the fetus.

In 1924, independent of the research of Herbert Evans and Katharine Bishop, Bennett Sure of the University of Arkansas showed that a compound removed from a diet induced sterility in male rats. Bennett Sure calls this compound Vitamin E, with the letters $\mathrm{A}, \mathrm{B}$ and $\mathrm{C}$ already in use and the letter $\mathrm{D}$ being predicted for an anti-cholitic factor. Vitamin $\mathrm{E}$ also receives the name tocopherol, from the Greek tokos: Progeny and pherein: To carry.

Herbert Evans and Oliver Emerson succeeded in isolating vitamin $\mathrm{E}$ from wheat germ oil in 1936 and Erhard Fernholz determined its structure in 1938. In the same year, the Nobel Prize in Chemistry Paul Karrer synthesized the Racemic alpha-tocopherol. It was not until 1968 that vitamin $\mathrm{E}$ was recognized as an essential nutrient for humans by the National Research Council of the United States.

The organism continuously produces free radicals, highly reactive compounds with single electrons. Free radicals damage cellular components as diverse as proteins, lipids or DNA. Radical reactions propagate in a chain: Molecules destabilized by a single electron become in turn free radicals. Antioxidants have the role of stopping this process by neutralizing free radicals, to reduce their harmfulness. Thus, vitamin $\mathrm{E}$ has the ability to capture and stabilize (by resonance) the single electron free radicals.

It is prescribed either in milligrams or in international units: 1 IU of Vitamin $\mathrm{E}$ is the biological equivalent of approximately 0.667 milligrams of d-alpha-tocopherol (2/3 mg exactly), or $1 \mathrm{mg}$ of dl-alpha-tocopherol acetate.

Vitamin E deficiency causes neuromuscular problems such as myopathies (degeneration of muscle tissue), disorders of the retina or the immune system.

In addition to its antioxidant role, vitamin $\mathrm{E}$ avoids the excessive aggregation of platelets responsible for thrombosis, has a protective action on red blood cells and could prevent, in this way, cardio-vascular diseases of atheromatous origin. In practice, however, no such action has been demonstrated. In addition, it would increase the rate of hemorrhagic stroke.

Vitamin E also has a beneficial effect on cholesterol levels. Although Evans' observations showed the importance of vitamin $\mathrm{E}$ on the fertility of certain animals, no effect was found in humans.

It could also protect from Parkinson's disease by preventing oxidation of omega-3 fatty acids and iron.

A 2011 study on Alzheimer's disease shows a lower concentration of vitamin $\mathrm{E}$ in people with Alzheimer's than healthy people. The researchers believe that the 8 forms of vitamin $\mathrm{E}$ could protect the disease or slow its development, much more effectively than using alpha-tocopherol alone.

Vitamin $\mathrm{E}$ is found in vegetable oils, mainly in prickly pear oil, wheat germ oil, unrefined palm oil (red) and in sunflower, soybean, Groundnut or olive. It is also found in smaller quantities in cereals, almonds, green vegetables, butter, margarine and fatty fish.

\section{Discussion}

Treatment with chemical drugs and surgery can at most stop some unpleasant symptoms and even control the heart, but generally does not correct due to the 
occurrence of the disease and therefore can't generally produce a real recovery of the patient, them having more of a role for maintaining and monitoring vital functions.

In 1953, Dr. G. C. Willis, M.D., (a Canadian doctor) first formulated the principle that all cardiovascular diseases are linked to a deficiency of vitamin $\mathrm{C}$ (ascorbic acid) in the body. He found that plaques and inflammation occurring in the blood of patients were due to deficiency of vitamin $\mathrm{C}$ in the body. Based on the idea already known that humans can't synthesize their own vitamin C like they do generally animals is needed in many situations a filler daily vitamin $\mathrm{C}$ in the body, either naturally (from food) or synthetic (when required doses are higher) (Willis, 1953; 1957; Willis et al., 1954).

In the $1980 \mathrm{~s}$, medical research led to the theory that heart disease starts with a fracture (or stress) produced in the arterial wall. The human body defends itself by producing single in liver lipoprotein (a) stored as plaque in order to repair the damaged artery wall (These materials they gave a Nobel prize in medicine in 1985). The theory was then supported by German researchers, led by Dr. Beisiegel, which examined post mortem plaques and found only lipoprotein (a) but did not found and cholesterol considered "bad" (LDL cholesterol). Pauling and Rath have understood then that lack of vitamin $C$ (which can't be manufactured by the liver) force liver to produces and uses instead of vitamin $\mathrm{C}$ lipoprotein (a) for the reconstruction of the broken blood vessels.

That was understood that chronic heart disease represents only a consequence of chronic scurvy (lack of vitamin $\mathrm{C}$ prolonged). The liver produces and stores in its place the plaque to repair the tissue absented. But this thread (reserve) has no elasticity and superior properties of fabrics produced normally with the help of vitamin C. On the other hand, needed reconstruction plaque behaves as a concrete, depositing it in large quantities and obstructing the arteries.

Alternative medicine, herbal, has made available to patients (over time) more effective treatment options therapies used varying in function on the specificity and seriousness of the case. One way general treatment was initiated and then generalized in 1989 (after many successful experiments, clinical and then patented in 1994 in the US) by Dr. Linus Pauling, Ph.D. and Dr. Mathias Roth, MD, the treatment being known as "Pauling Therapy" (Rath and Pauling, 1990).

Pauling therapy is consisting primarily of high doses of vitamin $\mathrm{C}$ designed to eliminate scurvy installed in the body but also to simultaneously increase collagen production to begin reworking so (natural) the arteries and eliminate already filed plaque. Secondly, treatment Pauling has in regard the administration of type amino acid lysine in large quantities with the obvious aim to combine immediately with lipoprotein (a) from the blood and stop them thus to create the plaque on arterial walls (Rath and Pauling, 1990).

Some researchers of the University of California reports that patients taking daily minimum of 500 milligrams of vitamin $\mathrm{C}$ as a dietary supplement, managed everyone to drop naturally (this way) CReactive Protein (CRP) in the blood by 24 percent after about two months of sustained treatment. More recent studies suggest that CRP is a far better predictor of heart disease than cholesterol. C-reactive protein is a real indicator of inflammation in the blood and body and there is today evidence that large chronic inflammation generates both the risk of heart disease or the occurrence of a stroke, but also an increased risk of producing a shape diabetes, Alzheimer's disease or other serious diseases (Dr. Gladys Block, UC Berkeley professor) (Gladys Block).

Dr. James Enstrom (University of California) investigated the benefits of the addition of $300 \mathrm{mg}$ vitamin $C$ daily (food supplement) on 11,000 people in over ten years. He showed that this additional minimal amount administered daily $(300 \mathrm{mg}$ vitamin $\mathrm{C}$ ), reduces the risk of heart disease by $50 \%$ in men and $40 \%$ in women (Enstrom, 2014).

G.C. Willis doctor found that all those who consumed $1,500 \mathrm{mg}$ daily dietary supplement of vitamin $\mathrm{C}$, within a year, managed to remove plaque from arteries and those who did not receive the treatment with vitamin $\mathrm{C}$ have suffered an increase of plaque (Willis, 1953; 1957; Willis et al., 1954).

Dr. Sydney Bush has developed a way to test the existence of plaque in the arteries by optometry (photo retina).

He could track and assess accurately the existence and plaque thickness deposited in the arteries by this ingenious way of diagnosis. The method was devised in 2002 after being tested on more patients, some of whom were treated daily with vitamin C (Vitamin C Foundation). The method can accurately predict the amount of vitamin $\mathrm{C}$ present in an organism and additional daily needs.

Vitamin C (ascorbic acid) contributes to a wide range of benefits. Vitamin $\mathrm{C}$ is known to perform several critical functions within the body involving such as: Detoxification, tissue-building, strengthen the immune system, pain control and control or kill pathogens. It is known to be helpful for wound and bone healing, healthy skin and eyes, fighting infections, stress management, toxic exposure and repair damaged tissue of all kinds.

Richard T. Lee, MD, led a team of researchers from Harvard Medical School, in order to test the 880 chemical compounds (all already authorized for use in humans in medicines, supplements, etc.) on their effect on stem cells embryo (in this case collected from mice). All stem cells used were initially treated to emit a 
certain color green when developed in heart muscle cells and only one chemical issue (from all 880 tested) managed to promote stem cell activity, which is just vitamin $\mathrm{C}$ (Richard Lee).

Vitamin $\mathrm{C}$ has been used in tandem with vitamin $\mathrm{K} 3$ in order to realize an auxiliary treatment against cancer, because vitamin $\mathrm{C}$ is the main antioxidant independent, playing a key role in protecting healthy cells against oxidative stress. When vitamin $\mathrm{C}$ is used in combination with other antioxidants such as glutathione and other drugs such as magnesium, sodium and optionally iodine, it can cause considerable damage to cancer cells, without affecting the healthy cells.

The Nurses' Health Study of more than 87000 American nurses aged 34-59 showed that taking more than 200 ius a day of vitamin $E$ reduces the risk of cardiovascular disease by $34 \%$ (Ajith et al., 2009; Atasayar et al., 2009; Babaev et al., 2010; Gladys Block; Hickey and Roberts, 2007; Kalender et al., 2010; Marín et al., 2014; Nakata and Maeda, 2002; Pierce et al., 2013; Rath and Pauling, 1990; Sun et al., 2000; Ulatowski et al., 2011; 2014; Ulatowski and Manor, 2015; Yévenes et al., 2012).

Dr Charles Hennekens studied more than 22000 physicians aged 40-84, with existing cardiovascular disease. He showed that all his patients which already have a heart condition, only $50 \mathrm{mg}$ a day of betacarotene (vitamin A) could reduce the risk of a heart attack or stroke by $50 \%$ (Charles Hennekens).

The Cambridge Heart Antioxidant Study patients with atherosclerosis were given 400ius or 800ius of vitamin $\mathrm{E}$, or a placebo. Those on vitamin E supplements had $47 \%$ fewer heart attacks than those on the placebo (Ajith et al., 2009; Atasayar et al., 2009; Babaev et al., 2010; Gladys Block; Hickey and Roberts, 2007; Kalender et al., 2010; Marín et al., 2014; Nakata and Maeda, 2002; Pierce et al., 2013; Rath and Pauling, 1990; Sun et al., 2000; Ulatowski et al., 2011; 2014; Ulatowski and Manor, 2015; Yévenes et al., 2012).

In Japan a 20-year study of over 2000 patients showed that optimum vitamin $\mathrm{C}$ intake was the single most important factor in preventing strokes (Matsuda et al., 1992; Nakata and Maeda, 2002; Sun et al., 2000).

Dr Sudhir Kurl of the University of Kuopio, Finland conducted a study of more than 2400 overweight patients who had high blood pressure. It was demonstrated that a low level of vitamin $\mathrm{C}$ made the risk of a stroke three times greater (Kunutsor et al., 2016).

All these studies show conclusively that the secret to avoiding or curing cardiovascular disease is to supplement your diet with vitamins, most importantly vitamin C, but also vitamins A and E (Ajith et al., 2009; Atasayar et al., 2009; Babaev et al., 2010; Gladys Block; Hickey and Roberts, 2007; Kalender et al., 2010; Marín et al., 2014; Nakata and Maeda, 2002; Pierce et al.,
2013; Rath and Pauling, 1990; Sun et al., 2000; Ulatowski et al., 2011; 2014; Ulatowski and Manor, 2015; Yévenes et al., 2012).

All these studies mentioned range from 6 years old to over half a century. Yet still today doctors are treating heart disease with artificial chemicals designed to block symptoms and which often have serious side effects, rather than look at the cause of the problem. Yes, there is talk about the benefits of exercise, giving up smoking and even of eating healthily. But how many doctors actually treat heart disease with vitamin $\mathrm{C}$ ?

Why do they use beta-blockers and all the other drugs instead of something that really works? The sad truth is, it comes down to money-the drugs make millions for the big drug companies, far more than they could make selling vitamin $\mathrm{C}$ and the drug companies have a large say in how doctors are trained.

If we want to find out more we may read 'Why Animals Don't Get Heart Attacks - But People Do!' by Dr Matthias Rath (Rath and Pauling, 1990; Rath, 2003).

We need supplements to get enough vitamin $C$, but natural sources are important too. Fresh fruits and vegetables have lots of different nutrients and fibre too (Buzea et al., 2015; Calderon et al., 2002; El-Gendy et al., 2009; Enstrom, 2014; Gladys Block; Ha et al., 2010; Hansen et al., 2014; Hickey and Roberts, 2007; Kalender et al., 2010; Kunutsor et al., 2016; Marín et al., 2014; Matsuda et al., 1992; Nakata and Maeda, 2002; Nefic, 2001; Noh et al., 2005; Petrescu et al., 2015; Petrescu and Petrescu, 2015; Pierce et al., 2013; Rath and Pauling, 1990; Rath, 2003; Ravnskov, 2009; Salama et al., 2013; Santos et al., 2008; Seo and Lee, 2002; Shalan et al., 2005; Sun et al., 2000; Ulatowski et al., 2011; 2014; Ulatowski and Manor, 2015; Verrax et al., 2003; Verrax and Calderon, 2008; Vitamin C Foundation; WALTER BLUMER; Willis, 1953; 1957; Willis et al., 1954; WSite of Richard T. Lee; WSite Charles Hennekens; Xavier et al., 2007; Yévenes et al., 2012; Yilmaz et al., 2006; Robert F. Cathcart; Yousef, 2004; Vitamine C. Wikipedia).

\section{Humans cannot make Vitamin $C$ in their Liver as all other Animals do}

Our ancestors have undergone a genetic mutation about 50 million years ago, the mutation that caused the final enzyme in the liver vitamin $\mathrm{C}$ synthesis to disappear. For this reason the human liver has not made it and was so ordinary. Principal missing enzyme is called Gulonolactone Oxidase (GLO). In animals it appears and fulfills its function of vitamin $\mathrm{C}$ production in the liver. However, there are some animals such as gorillas, chimpanzees and orangutans which share the same mutation GLO and also can't produce vitamin C.

These primates can also have cardiovascular disease, if their food do not donate them enough vitamin C. Except for humans and primates, all other animals have 
the three enzymes in the liver which can synthesize vitamin $\mathrm{C}$ from glucose (a simple sugar).

Another exception is the guinea pig (guinea pig, a rodent). Guinea pig, for reasons not fully understood yet suffered the same genetic mutation as people and he was deprived of GLO enzyme. However this is extremely advantageous for us humans as guinea pig can be used in various experiments needed to study the mechanisms that generate human disease (Fig. 2) (Barja et al., 1994).

The gorillas which lack the ability to synthesize vitamin $\mathrm{C}$ also get heart disease (Fig. 3).

The chimpanzees which lack the ability to synthesize vitamin $\mathrm{C}$ also get heart diseases (Fig. 4).

The orangutans which lack the ability to synthesize vitamin $\mathrm{C}$ also get heart diseases (Fig. 5).

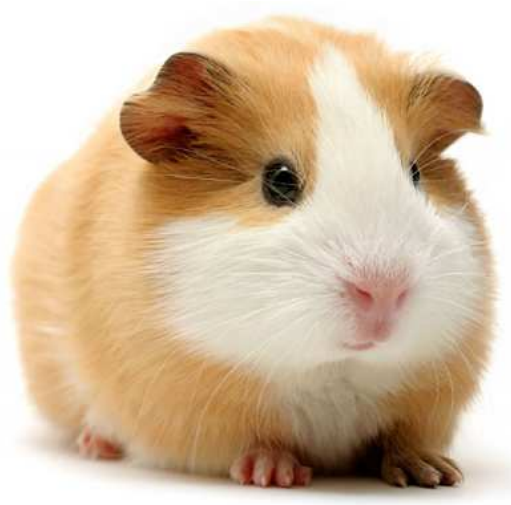

Fig. 2. Guinea pig which lacks the ability to synthesize vitamin C, also gets heart diseases

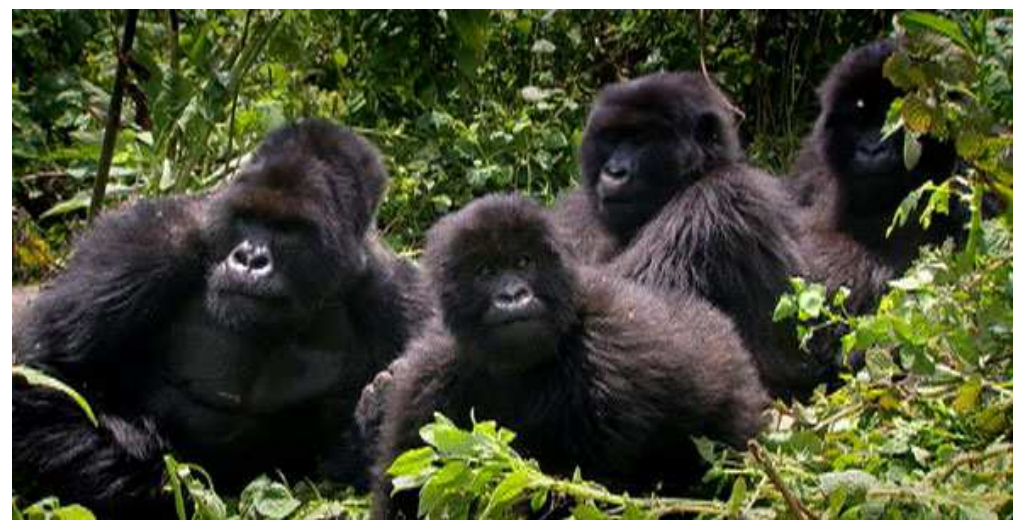

Fig. 3. The gorillas which lack the ability to synthesize vitamin $\mathrm{C}$ also get heart diseases

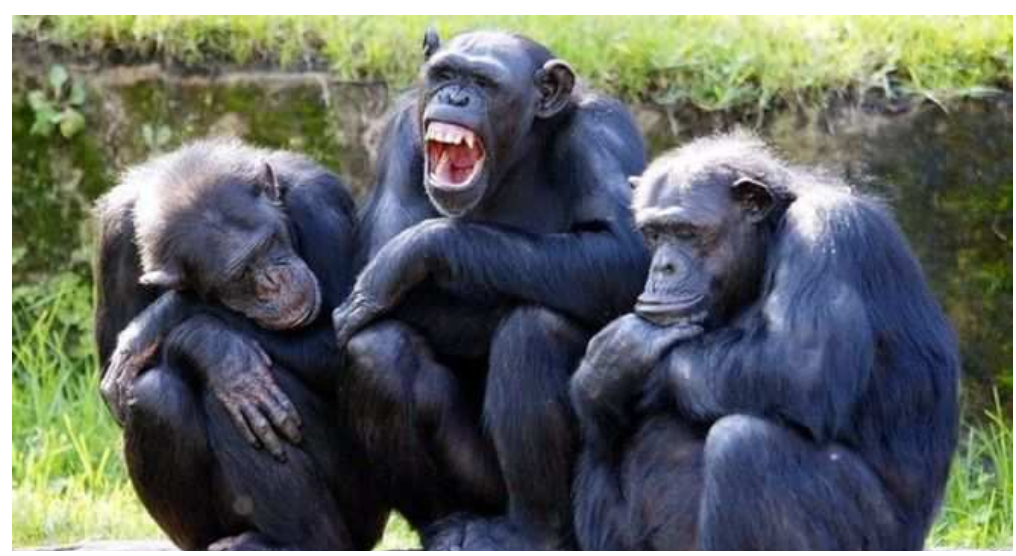

Fig. 4. The chimpanzees which lack the ability to synthesize vitamin $\mathrm{C}$ also get heart diseases 


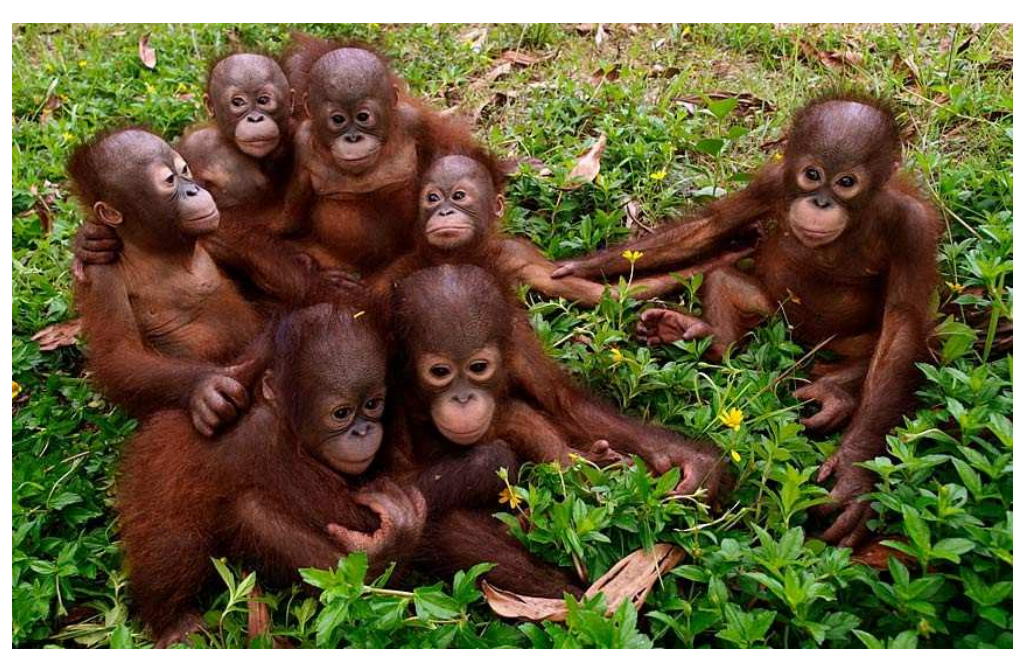

Fig. 5. The orangutans which lack the ability to synthesize vitamin $\mathrm{C}$ also get heart disease

The renowned Canadian physician, G. C. Willis, led a research on mice in 1950 where it was demonstrated that these pets once deprived of vitamin $\mathrm{C}$ develop atherosclerotic plaques, while rats who consumed vitamin $\mathrm{C}$ in large quantities were completely protected. In addition rats deprived of vitamin $\mathrm{C}$ developed lipoprotein (a) and formed arterial plaques (Willis, 1953; 1957; Willis et al., 1954).

Hickey and Roberts (2007) have shown in their book and made the statement "Vitamin $\mathrm{C}$ and Tocotrienols can reverse coronary artery disease".

The protective effect of the pre-treatment with vitamin $\mathrm{C}$ against imidacloprid-induced oxidative stress in liver mice is better than the post-treatment (El-Gendy et al., 2009).

Deficiency of alkaline and acid DNase is a hallmark in all non-necrotic cancer cells in animals and humans. These enzymes are reactivated at early stages of cancer cell death by vitamin C (acid DNase) and vitamin $\mathrm{K}(3)$ (alkaline DNase). Moreover, the coadministration of these vitamins (in a ratio of $100: 1$, for $\mathrm{C}$ and $\mathrm{K}(3)$, respectively) produced selective cancer cell death. The aim is to prepare the introduction of the association of vitamins $\mathrm{C}$ and $\mathrm{K}(3)$ into human clinics as a new, nontoxic adjuvant cancer therapy (Calderon et al., 2002; Verrax et al., 2003; Verrax and Calderon, 2008; Vitamin C Foundation).

\section{Conclusion}

Professor KF Gey (University of Bern, Switzerland) had the idea to do a comparative study on geographical areas, representative levels of vitamins from blood, on average (among others being considered and vitamin $\mathrm{C}$ and beta-carotene) and rates of cardiovascular systems become ill. Thus he learned that at the people living to northern Europe, rates of heart diseases are much higher compared to the population of southern Europe, vitamins levels being generally better for the southern (where warmer, more sunny and having their own culture of vegetables, herbs and fruits more developed which obviously lead to higher consumption and natural vitamins). So he could shoot and an important conclusion, regarding the fact that vitamins levels multiple, massive and constant especially with vitamins $\mathrm{C}, \mathrm{E}$ and $\mathrm{A}$ has a much greater impact on eliminating the risk of heart attack or diseases of the heart than reduce cholesterol levels by various diets (Gladys).

This helps us to synthesize the basic conclusion of this work: Rather than struggle with different diets, trying to eliminate bad cholesterol in our diets, it is more useful to us all, as of a certain age up to begin to consume more vitamin $\mathrm{C}$ daily. Obviously it needs to take every day the vitamin $\mathrm{C}$ directly from foods rich in vitamin $\mathrm{C}$, such as many lemons, oranges, grapefruit, peppers, cabbage, broccoli, blueberries, onions, tomatoes, grapes, etc. But when health problems begin to emerge (or feel) it is mandatory to complete daily dose of vitamin $\mathrm{C}$ and with a concentrated supplement (synthesized). Generally a daily dose of $1000 \mathrm{mg}$ is sufficient regardless of age. However in people already affected by heart or have deposits of plaque in the arteries, the minimum amount needed of extra vitamin $\mathrm{C}$ is $2 \mathrm{~g}$ daily. For people who have already suffered a heart attack or stroke, it is needed an urgent and sustained treatment with high doses of 3000-7000 $\mathrm{mg}$ vitamin $\mathrm{C}$ daily.

We are addicted to vitamins $\mathrm{C}$ and $\mathrm{E}$. But vitamin $\mathrm{E}$ can't be taken anyway. You must follow the directions of a physician. Usually vitamin E should be consumed together with vitamin $\mathrm{K}$, but the optimum dose should be given by a specialist.

The collagen of our body is the protein that is present in the largest quantity and is essential role to build and rebuild connective tissue, teeth, bones, arteries, hair, etc. 
We can't have a powerful enough collagen without the presence of vitamin $\mathrm{C}$ in sufficient quantities.

Our ancestors have undergone a genetic mutation about 50 million years ago, the mutation that caused the final enzyme in the liver vitamin $C$ synthesis to disappear. For this reason the human liver has not made it and was so ordinary. Principal missing enzyme is called GLO (gulonolactone oxidase). In animals it appears and fulfills its function of vitamin $\mathrm{C}$ production in the liver.

\section{Acknowledgement}

This text was acknowledged and appreciated by Assoc. Pro. Taher M. Abu-Lebdeh, North Carolina A and T State Univesity, United States, Muftah H. El-Naas PhD MCIC FICCE QAFCO Chair Professor in Chemical Process Engineering Gas Processing Center College of Engineering Qatar University, Professor Guanying Chen Harbin Institute of Technology and SUNY Buffalo China and (Ms.) Shweta Agarwala Senior Research Scientist at Singapore Center for 3D Printing Nanyang Technological University Singapore, whom we thanks and in this way.

\section{Author's Contributions}

All the authors contributed equally to prepare, develop and carry out this manuscript.

\section{Ethics}

This article is original and contains unpublished material. The corresponding author confirms that all of the other authors have read and approved the manuscript and no ethical issues involved.

\section{References}

Abdul-Razzak, K., K. Alzoubi, S. Abdo and W. Hananeh, 2012. High-dose vitamin C: Does it exacerbate the effect of psychosocial stress on liver? Biochemical and histological study. Exp. Toxicol. Pathol., 64: 367-371. DOI: 10.1016/j.etp.2010.09.011

Abou-Zeid, N.R.A., 2014. Ameliorative effect of vitamin $\mathrm{C}$ against 5-fuorouracil-induced hepatotoxicity in mice: A light and electron microscope study. J. Basic Applied Zool., 67: 109-118. DOI: 10.1016/j.jobaz.2013.12.004

Ahmed, E., H. Omar, S. Elghaffar, S. Ragb and A. Nasser, 2011. The antioxidant activity of Vitamin C, DPPD and 1-cysteine against Cisplatin-induced testicular oxidative damage in rats. Food Chem. Toxicol., 49: 1115-1121. DOI: $10.1016 /$ j.fct.2011.02.002

Ajith, T.A., S. Usha and V. Nivitha, 2007. Ascorbic acid and $\alpha$-tocopherol protect anticancer drug cisplatin induced nephrotoxicity in mice: A comparative study, Clin. Chim. Acta, 375: 82-86.

DOI: $10.1016 /$ j.cca.2006.06.011
Ajith, T.A., G. Abhishek, D. Roshny and N.P. Sudheesh, 2009. Co-supplementation of single and multi doses of vitamins $\mathrm{C}$ and $\mathrm{E}$ ameliorates cisplatin-induced acute renal failure in mice. Exp. Toxicol. Pathol., 61: 565-571. DOI: 10.1016/j.etp.2008.12.002

Antunes, L.G., J.D. Darin and M.D.L. Bianchi, 2000. Protective effects of Vitamin $\mathrm{C}$ against cisplatininduced nephrotoxicity and lipid peroxidation in adult rats: A dose-dependent study. Pharmacol. Res., 41: 405-411. DOI: 10.1006/phrs. 1999.0600

Atasayar, S., H. Gürer-Orhan, B. Gürel, G. Girgin and H. Özgünes, 2009. Preventive effect of aminoguanidine compared to vitamin $\mathrm{E}$ and $\mathrm{C}$ on cisplatin-induced nephrotoxicity in rats. Exp. Toxicol. Pathol., 61: 23-32.

DOI: $10.1016 /$ j.etp.2008.04.016

Babaev, V.R., L. Li, S. Shah, S. Fazio and M.F. Linton et al., 2010. Combined Vitamin C and Vitamin E deficiency worsens early atherosclerosis in apolipoprotein e-deficient mice. Arteriosclerosis Thrombosis Vascular Biol., 30: 1751-1757. DOI: 10.1161/ATVBAHA.110.209502

Babaev, V.R., R.R. Whitesell, L. Li, M.F. Linton and S. Fazio et al., 2011. Selective macrophage ascorbate deficiency suppresses early atherosclerosis. Free Radic Biol. Med., 50: 27-36. DOI: 10.1016/j.freeradbiomed.2010.10.702

Barja, G., M. Lopez-Torres, R. Perez-Campo, C. Rojas and S. Cadenas et al., 1994. Dietary vitamin C decreases endogenous protein oxidative damage, malondialdehyde and lipid peroxidation and maintains fatty acid unsaturation in the guinea pig liver. Free Radical Biol. Med., 17: 105-115.

DOI: 10.1016/0891-5849(94)90108-2

Buzea, E., F.L. Petrescu, L. Nănuţ, C. Nan and M. Neacşa, 2015. Mechatronic system to determine the concentration of carotenoids, analele univers. Craiova Biol. Horticul. Tehn. Prel. Prod. Agr. Ing. Med., 20: 371-376.

Calderon, P.B., J. Cadrobbi, C. Marques, N. Hong-Ngoc and J.M. Jamison et al., 2002. Potential therapeutic application of the association of vitamins C and K3 in cancer treatment. Curr. Med. Chem., 9: 2271-2285. DOI: $10.2174 / 0929867023368674$

El-Gendy, K.S., N.M. Aly, F.H. Mahmoud, A. Kenawy and A.K. El-Sebae, 2009. The role of vitamin C as antioxidant in protection of oxidative stress induced by imidacloprid. Food Chem. Toxicol., 48: 215-221. DOI: $10.1016 /$ j.fct.2009.10.003

Enstrom, J., 2014. Food and you: Feeding the world with modern agricultural biotechnology. American Council on Science and Health.

Gladys Block. http://sph.berkeley.edu/gladys-block 
Ha, H.L., H.J. Shin, M.A. Feitelson and D.Y. Yu, 2010. Oxidative stress and antioxidants in hepatic pathogenesis. World J. Gastroenterol., 16: 6035-6043. DOI: 10.3748/WJG.v16.i48.6035

Hansen, S.N., P. Tveden-Nyborg and J. Lykkesfeldt, 2014. Does vitamin $\mathrm{C}$ deficiency affect cognitive development and function? Nutrients, 6: 3818-3846. DOI: $10.3390 /$ nu6093818

Hickey, S. and H. Roberts, 2007. The Cancer Breakthrough. 1st Edn., Lulu.com, ISBN-10: 1430323000, pp: 96.

Kalender, S., F.G. Uzun, D. Durak, F. Demir and Y. Kalender, 2010. Malathion-induced hepatotoxicity in rats: The effects of vitamins $\mathrm{C}$ and $\mathrm{E}$. Food Chem. Toxicol., 48: 633-638. DOI: 10.1016/j.fct.2009.11.044

Kunutsor, S., S. Kurl, F. Zaccardi and J. Laukkanen, 2016. Baseline and long-term fibrinogen levels and risk of sudden cardiac death: A new prospective study and meta-analysis. Atherosclerosis, 245: 171-180. DOI: 10.1016/j.atherosclerosis.2015.12.020

Marín, T., P. Contreras, J.F. Castro, D. Chamorro and E. Balboa et al., 2014. Vitamin E dietary supplementation improves neurological symptoms and decreases c-Abl/p73 activation in Niemann-Pick C mice. Nutrients, 6: 3000-3017. DOI: $10.3390 /$ nu6083000

Matsuda, T., H. Tanaka, S. Shimazaki, H. Matsuda and H. Abcarian et al., 1992. High-dose vitamin C therapy for extensive deep dermal burns. Burns, 18: 127-131. DOI: 10.1016/0305-4179(92)90009-J

Nakata, Y. and N. Maeda, 2002. Vulnerable atherosclerotic plaque morphology in apolipoprotein E-deficient mice unable to make ascorbic Acid. Circulation, 105: 1485-1490. PMID: 11914259

Nefic, H., 2001. Anticlastogenic effect of Vitamin C on cisplatin induced chromosome aberrations in human lymphocyte cultures. Mutat. Res. Genetic Toxicol. Environ. Mutagenesis, 498: 89-98. DOI: 10.1016/S1383-5718(01)00269-8

Noh, K., H. Lim, S.K. Moon, J.S. Kang and W.J. Lee et al., 2005. Mega-dose Vitamin C modulates $\mathrm{T}$ cell functions in Balb/c mice only when administered during T cell activation. Immunol. Lett., 98: 63-72. DOI: 10.1016/j.imlet.2004.10.012

Petrescu, F.L., E. Buzea, L. Nănuţ, M. Neacşa and C. Nan, 2015. The role of antioxidants in slowing aging of skin in a human. Analele Univers. Craiova Biol. Horticul. Tehn. Prel. Prod. Agr. Ing. Med., 20: 567-574.

Petrescu, F. and R. Petrescu 2015. Alternative energy magazine. Energy From Stars.

Pierce, M.R., D.L. Diasio, L.M. Rodrigues, F.E. Harrison and J.M. May, 2013. Combined vitamin C and $\mathrm{E}$ deficiency induces motor defects in gulo $^{-/-}$ ${ } \mathrm{SVCT}^{+/-}$mice. Nutr. Neurosci., 16: 160-173. DOI: 10.1179/1476830512Y.0000000042
Rath, M. and L. Pauling, 1990. Hypothesis: Lipoprotein(a) is a surrogate for ascorbate. Proc. Nat. Acad. Sci. USA., 87: 6204-6207.

DOI: $10.1073 /$ pnas.87.16.6204

Rath, M., 2003. Why Animals Don't Get Heart Attacks-But People Do!. 4th Edn., MR Pub., Santa Clara, ISBN-10: 0967954681, pp: 319.

Ravnskov, U., 2009. Fat and Cholesterol are Good for You. 1st Edn., GB Publishing, ISBN-10: 919755538X, pp: 234.

Robert F. Cathcart, M.D. http://www.doctoryourself.com/biblio_cathcart.html

Salama, Z.A., F.K. El Baz, A.A. Gaafar and M.F. Zaki, 2013. Antioxidant activities of phenolics, flavonoids and vitamin $\mathrm{C}$ in two cultivars of fennel (Foeniculum vulgare Mill.) in responses to organic and bio-organic fertilizers. J. Saudi Society Agric. Sci., 14: 91-99. DOI: 10.1016/j.jssas.2013.10.004

Santos, L., R.L.M. Freitas, S. Xavier, G. Saldanha and R.M. Freitas, 2008. Neuroprotective actions of vitamin $\mathrm{C}$ related to decreased lipid peroxidation and increased catalase activity in adult rats after pilocarpine-induced seizures. Pharmacol. Biochem. Behav., 89: 1-5. DOI: 10.1016/j.pbb.2007.10.007

Seo, M.Y. and S.M. Lee, 2002. Protective effect of low dose of ascorbic acid on hepatobiliary function in hepatic ischemia/reperfusion in rats. J. Hepatol., 36: 72-77. DOI: $10.1016 / \mathrm{S} 0168-8278(01) 00236-7$

Shalan, M.G., M.S. Mostafa, M.M. Hassouna, H. El-Nabi and A. El-Refaie, 2005. Amelioration of lead toxicity on rat liver with Vitamin $\mathrm{C}$ and silymarin supplements. Toxicology, 206: 1-15. DOI: $10.1016 /$ j.tox.2004.07.006

Sun, F., S. Hayami, Y. Ogiri, S. Haruna and K. Tanaka et al., 2000. Evaluation of oxidative stress based on lipid hydroperoxide, vitamin C and vitamin $\mathrm{E}$ during apoptosis and necrosis caused by thioacetamide in rat liver. Biochim. Biophys. Acta (BBA)-Molecular Basis Dis., 1500: 181-185.

DOI: 10.1016/S0925-4439(99)00100-3

Ulatowski, L., R. Parker, C. Davidson, N. Yanjanin and T.J. Kelley et al., 2011. Altered vitamin E status in Niemann-Pick type C disease. J. Lipid Res., 52: 1400-1410. DOI: 10.1194/jlr.M015560

Ulatowski, L., R. Parker, G. Warrier, R. Sultana and D.A. Butterfield et al., 2014. Vitamin E is essential for Purkinje neuron integrity. Neuroscience, 260: 120-129. DOI: 10.1016/j.neuroscience.2013.12.001

Ulatowski, L.M. and D. Manor, 2015. Vitamin E and neurodegeneration. Neurobiol. Dis., 84: 78-83. DOI: $10.1016 /$ j.nbd.2015.04.002 
Verrax, J., J. Cadrobbi, M. Delvaux, J.M. Jamison and J. Gilloteaux et al., 2003. The association of vitamins C and $\mathrm{K} 3$ kills cancer cells mainly by autoschizis, a novel form of cell death. Basis for their potential use as coadjuvants in anticancer therapy. Eur. J. Med. Chem., 38: 451-457. DOI: 10.1016/S0223-5234(03)00082-5

Verrax, J. and P.B. Calderon, 2008. The controversial place of vitamin $\mathrm{C}$ in cancer treatment. Biochem. Pharmacol., 76: 1644-1652. DOI: $10.1016 /$ j.bcp.2008.09.024

Vitamin $\mathrm{C}$ Foundation. http://www.vitamincfoundation.org/bush/

Vitamine C. Wikipedia. https://fr.wikipedia.org/wiki/Vitamine C

WALTER BLUMER. http://mmscr.timeclever.com/hallof-fame/dr-walter-blumeredta/

Willis, G.C., 1953. An experimental study of intimal ground substance in atherosclerosis. Can. Med. Assoc. J., 69: 17-22. PMID: 13059725

Willis, G.C., A.W. Light and W.S. Gow, 1954. Serial Arteriography in Atherosclerosis in Human Beings. Can. Med. Assoc. J., 71: 562-568.

Willis, G.C., 1957. The reversibility of atherosclerosis. Can. Med. Assoc. J., 77: 106-108. PMID: 13446787

WSite of Richard T. Lee, MD. http://hsci.harvard.edu/people/richard-lee-md
WSite Charles Hennekens, MD. http://flhealthinnovation.org/charles-hennekens/

Xavier, S.M., C.O. Barbosa, D.O. Barros, R.F. Silva and A.A. Oliveira et al., 2007. Vitamin C antioxidant effects in hippocampus of adult Wistar rats after seizures and status epilepticus induced by pilocarpine. Neurosci. Lett., 420: 76-79. DOI: 10.1016/j.neulet.2007.04.056

Yévenes, L.F., A. Klein, J.F. Castro, T. Marín and N. Leal et al., 2012. Lysosomal vitamin E accumulation in niemann-pick type c disease. Biochim. Biophys. Acta, 1822: 150-160. DOI: 10.1016/j.bbadis.2011.11.009

Yilmaz, S., A. Atessahin, E. Sahna, I. Karahan and S. Ozer, 2006. Protective effect of lycopene on adriamycininduced cardiotoxicity and nephrotoxicity. Toxicology, 218: 164-171. DOI: $10.1016 /$ j.tox.2005.10.015

Yousef, M., 2004. Aluminium-induced changes in hemato-biochemical parameters, lipid peroxidation and enzyme activities of male rabbits: Protective role of ascorbic acid. Toxicology, 199: 47-57. DOI: $10.1016 /$ j.tox.2004.02.014 